\title{
Insecticide-treated nets ownership and utilization among under-five children following the 2010 mass distribution in Burkina Faso
}

Souleymane Diabaté ${ }^{1,2}$, Thomas Druetz ${ }^{1,2}$, Emmanuel Bonnet ${ }^{3}$, Seni Kouanda ${ }^{4}$, Valéry Ridde ${ }^{1,2}$ and Slim Haddad ${ }^{1,2^{*}}$

\begin{abstract}
Background: Periodic mass distributions contribute significantly to universal access to insecticide-treated nets (ITNs). However, due to the limited number of nets distributed, needs remain unsatisfied, particularly in large households.

Methods: This study was conducted in Kaya health district following the 2010 mass distribution of ITNs in Burkina Faso. Data were collected on the socio-economic and geo-spatial characteristics and ITN possession and utilization levels of 2,004 households. The study explored: 1) ITN access, in terms of intra-household saturation with ITNs (households with at least one ITN for every two members) correctly installed and in very good physical condition; and 2) factors influencing the decision to place under-five children under a net. Particular attention was given to vector control activities undertaken by mothers.
\end{abstract}

Results: Of the 2,004 households, 90\% possessed at least one ITN. However, intra-household saturation with ITNs was below $60 \%$ in small households and below $20 \%$ in large ones (>6 members). Crude proportion ratios comparing possession and levels of intra-household saturation with ITNs varied between 1.5 (small households) and 7.8 (large households). The proportions of households with ITNs for every two members that were correctly hung or in very good physical condition ranged from $0 \%$ to $6.5 \%$ in large households and $27.8 \%$ to $40.7 \%$ in small ones. ITN use to protect under-five children was lower in large households; it was significantly higher when there was at least one ITN for every two members. In large households, it was significantly higher when a child had experienced an episode of any illness in the previous two weeks and when the mother had taken actions to control vector proliferation. In small households, ITN use was significantly higher in families with agricultural land and children aged 12-23 months.

Conclusion: Ownership rates were high, but real access to bed nets remained limited. The allocation process disadvantages large families. Real access to bed nets implies they are available, properly installed, and in good condition. More post-campaign awareness-raising activities targeting preventive practices in households could foster more effective ITN use.

Keywords: Malaria, Under-five children, Saturation with bed nets, Vector control, Burkina Faso

\section{Background}

Malaria remains one of the leading causes of morbidity and mortality worldwide [1,2]. Sub-Saharan Africa is the most affected region, with more than $78 \%$ of all deaths occurring among under-five children [1]. In Burkina Faso, malaria is responsible for $22 \%$ of all deaths reported in

\footnotetext{
*Correspondence: slim.haddad@umontreal.ca

'University of Montreal Hospital Research Centre (CRCHUM), Montreal, Canada

${ }^{2}$ Department of Social and Preventive Medicine, University of Montreal, Montreal, Canada

Full list of author information is available at the end of the article
}

medical centres, and $60 \%$ of those malaria-related deaths occur among under-five children [3,4]. Insecticide-treated nets (ITNs) and indoor residual spraying (IRS), along with artemisinin-based combination therapy (ACT), are the cornerstones of vector control and malaria elimination $[1,5,6]$. Studies have reported a sizeable decline in malaria prevalence and mortality in sub-Saharan Africa following deployment of ACT and distribution of ITNs [5,7,8]. Between 2001 and 2010, malaria control interventions have helped prevent approximately 842,800 deaths among African children [9]. 
To accelerate universal access to bed nets, routine distribution of ITNs is often reinforced by periodic mass donations of fixed numbers of nets. Campaigns are aimed at increasing coverage-the proportion of households owning ITNs-and reducing social inequalities in bed net ownership and use [10-13]. However, due to the insufficient number of nets distributed, the needs of households, particularly large ones, are often not fulfilled. The possession of at least one net for every two members of the household is seldom achieved in large households [12,14]. For example, the proportion of households owning at least one ITN was $91 \%$ after the 2011 universal coverage campaign in Tanzania. At the same time, only $35 \%$ of households had at least one ITN for every two members [14].

In Burkina Faso, eight million ITNs were distributed between July 2009 and January 2010 [4,15]. Before the distribution, the number of members per household was calculated through a pre-campaign survey, and the plan was to give households one net for every two members. Unfortunately, the total number of ITNs acquired for the campaign was lower than projected. Accordingly, the national authorities decided, once the distribution was launched, to subtract one ITN for households with more than four members $[4,15]$.

Six months after the distribution campaign, this study was conducted in Kaya, in north-central Burkina Faso, to examine levels of accessibility to ITNs and their use among under-five children. Rather than focusing only on households' possession of ITNs, the analysis of accessibility examined the extent to which household members' needs were satisfied, as measured by an indicator reflecting intra-household saturation coverage in ITNs: the proportion of households owning at least one ITN for every two persons $[14,16]$, the proportion of correctly installed ITNs, and the proportion of ITNs in very good condition. These analyses examined both small and large households. The analysis of ITN use compared utilization levels according to geographic context. The main factors influencing the decision to place an under-five child under an ITN were also studied. To explore prevention practices, particular attention was given to the link between placing a child under an ITN and mothers' actions to curb vector proliferation.

\section{Methods}

\section{Study site}

Six months after the end of the campaign, a cross-sectional survey was conducted during the highest malaria transmission period of the rainy season (August-September 2011). The survey took place in the area covered by a population observatory-the Kaya Health and Demographic Surveillance System (Kaya HDSS) [17]. For the purpose of the study, a subsample of the panel of households surveyed by the observatory was used. The sample included 2,004 households randomly selected and stratified between urban sectors and rural areas (18 villages located within a radius of 20 kilometres around the city).

\section{Data collection and definition of main variables}

Information on the households' socio-economic, geographic, and spatial characteristics (socio-economic indicators, longitude and latitude, roads, lakes and sources of stagnant water) was extracted from the Kaya HDSS database. Households were geo-referenced through a global positioning system, and the villages' geographic boundaries were delimited by means of households' geographic centres and Thiessen polygons [18]. The ITNs owned by each household were numbered and, when allowed by the head of the household, the surveyor observed whether they were correctly hung (placement) and in very good physical condition. Surveyors were specifically trained for these observations. An ITN is correctly installed over the sleeping place when the four hanging points are used, it is at an appropriate height, and it fully covers the sleeping place, with no space between the net and the edges of the sleeping place. An ITN in good physical condition is one with no tears and no stretching of the standard mesh. Mothers were asked whether each child had slept under an ITN on the night preceding the survey. They also answered questions related to their knowledge, attitudes, and practices related to malaria prevention and treatment. Three of these questions concerned actions undertaken regularly to control vector proliferation: cleaning the house, eliminating stagnant water, and eliminating larval sites around the house. All under-five children were examined and their episodes of any illness over a two-week recall period were recorded.

Eight indicators of access and use for each household or eligible child were assessed: ITN ownership: 1) proportion of households with at least one ITN (the denominator being the total number of households surveyed); 2) intrahousehold saturation with ITNs, measured by the proportion of households with at least one ITN for every two people (the numerator being the number of households with at least one ITN for every two people and the denominator being the total number of households owning at least one ITN) [16]. ITN placement status above the sleeping place: the proportion of households with 3) all ITNs correctly hung; 4) at least one ITN correctly hung; 5) at least one ITN for every two people correctly hung. ITN physical condition: the proportion of households with 6) all ITNs in very good condition; 7) at least one ITN in very good condition; and 8) at least one ITN in very good condition for every two people; ITN use to protect underfive children: 8) number of under-five children who had slept under a bed net the previous night. 


\section{Data analysis}

Analyses of ITN access were stratified according to urban/peri-urban/rural areas [19] and household size (six members or less, and more than six). Crude proportion ratios (CPRs) were computed to compare: 1 ) household ITN ownership and intra-household saturation with ITNs (the proportion of households with at least one ITN divided by the proportion of households with at least one ITN for every two people); and 2) proportion of households with at least one ITN hung/in very good physical condition and proportion of households with at least one ITN for every two members hung/in very good physical condition (the denominator being the proportion of households with at least one ITN for every two members hung/in very good physical condition). Utilization rates among under-five children were also stratified by urban/peri-urban/rural areas and household size. Factors associated with use were studied through multilevel regression models, with children being nested within households and villages or urban sectors. Analyses were conducted using Arcgis 10.x ESRI [20] and Stata 13 software [21].

The study was approved by the Ethics Committee of the University of Montreal Hospital Research Centre and the Health Research Ethics Committee in Burkina Faso.

\section{Results}

\section{Sample and ITN characteristics}

The survey covered 2,004 households, 1,906 children, and 4,811 ITNs (Table 1). To reduce vector proliferation, mothers in half of the households had undertaken at least one of these actions: cleaning the house and/or eliminating stagnant water and/or eliminating larval sites around the house. There were no noticeable differences between urban, rural, and peri-urban settings. Nearly one child out of three had presented an episode of any illness during the two-week recall period. The great majority (90\%) of ITNs found in the homes were acquired during the campaign.

\section{Access to ITNs}

Ninety percent of all households possessed at least one ITN. Ownership increased with household size and in rural areas, where transmission is higher (Table 2). There were more than two members per ITN in less than one-third of small households, but in $80 \%$ of large ones. Consequently, the gap between possession and intra-household saturation

Table 1 Sample characteristics

\begin{tabular}{|c|c|c|c|c|c|c|c|}
\hline \multirow[t]{3}{*}{ Characteristic (proportion; \% or number; $\mathrm{n}$ ) } & \multirow[t]{3}{*}{ Overall } & \multirow{2}{*}{\multicolumn{3}{|c|}{$\begin{array}{c}\text { Small household } \\
\text { ( } \leq 6 \text { people) }\end{array}$}} & \multirow{2}{*}{\multicolumn{3}{|c|}{$\begin{array}{c}\text { Large household } \\
\text { (>6 people) }\end{array}$}} \\
\hline & & & & & & & \\
\hline & & Rural & Peri-urban & Urban & Rural & Peri-urban & Urban \\
\hline Households (n) & 2004 & 402 & 143 & 566 & 414 & 104 & 373 \\
\hline \multicolumn{8}{|l|}{ General characteristics } \\
\hline Median number of members (interquartile range) & $6(4-9)$ & $5(4-6)$ & $4(3-5)$ & $4(3-5)$ & $9(8-12)$ & $9(8-11)$ & $9(7-11)$ \\
\hline Own agricultural land & 52.2 & 67.4 & 49.0 & 21.9 & 85.8 & 74.0 & 40.0 \\
\hline Own any cattle ${ }^{\dagger}$ & 74.0 & 88.1 & 77.6 & 41.7 & 97.1 & 90.4 & 76.1 \\
\hline Access to private toilets & 61.0 & 26.6 & 41.3 & 95.1 & 29.0 & 43.3 & 94.4 \\
\hline Access to safe drinking water & 49.7 & 14.4 & 29.4 & 86.6 & 14.0 & 31.7 & 84.2 \\
\hline Distance to the nearest lake or stagnant water ( $<1000$ versus $\geq 1000$ metres) & 40.1 & 35.8 & 28.7 & 45.6 & 39.1 & 32.7 & 44.0 \\
\hline \multicolumn{8}{|l|}{ Vector control actions undertaken by the mother } \\
\hline House cleaning & 40.6 & 40.3 & 41.3 & 40.6 & 41.3 & 45.2 & 38.3 \\
\hline Elimination of stagnant water & 20.3 & 18.9 & 21.0 & 20.9 & 20.5 & 19.2 & 20.6 \\
\hline Elimination of larval sites & 28.3 & 28.9 & 24.5 & 28.8 & 27.5 & 28.9 & 29.2 \\
\hline Indicator = at least one of these three actions & 50.4 & 50.5 & 49.7 & 50.4 & 49.5 & 58.7 & 49.3 \\
\hline Under-five children (n) & 1,906 & 313 & 102 & 355 & 576 & 156 & 404 \\
\hline Proportion of under-five among all children present during the survey & 79.7 & 82.2 & 82.9 & 83.3 & 77.4 & 85.3 & 75.8 \\
\hline At least 1 episode of any illness during the preceding 2 weeks $^{\ddagger}$ & 30.6 & 30.0 & 29.7 & 31.9 & 29.2 & 25.0 & 35.0 \\
\hline Insecticide-treated nets $(n)$ & 4,811 & 766 & 262 & 922 & 1,430 & 311 & 1,119 \\
\hline Acquired from the campaign & 93.7 & 96.7 & 96.6 & 86.6 & 98.0 & 93.3 & 91.7 \\
\hline Age $\leq 12$ months & 96.6 & 97.9 & 97.3 & 92.7 & 98.7 & 97.4 & 95.8 \\
\hline ITNs observed & 62.5 & 66.6 & 69.5 & 70.4 & 56.4 & 57.9 & 60.7 \\
\hline
\end{tabular}

Notes: ITNs = insecticide-treated nets; Proportions or numbers in bold $=$ P value $<0.05$ (comparing urban/peri-urban/rural areas); ${ }^{\dagger}$ Beef, camel, goat, horse, pig or sheep; ${ }^{\ddagger}$ Among those present during the survey $(n=1,721)$. 
Table 2 Access to and characteristics of the insecticide-treated nets (ITNs)

\begin{tabular}{|c|c|c|c|c|c|c|c|}
\hline \multirow{2}{*}{$\begin{array}{l}\text { ITN indicator (proportion, \%; otherwise } \\
\text { indicated) }\end{array}$} & \multirow[t]{2}{*}{ Overall } & \multicolumn{3}{|c|}{ Small household ( $\leq 6$ people) } & \multicolumn{3}{|c|}{ Large household ( $>6$ people) } \\
\hline & & Rural & Peri-urban & Urban & Rural & Peri-urban & Urban \\
\hline \multicolumn{8}{|l|}{ Ownership $^{\dagger}$} \\
\hline Median number (IQR) & $2(2-3)$ & $2(2-2)$ & $2(1-2)$ & $2(1-2)$ & $3(3-4)$ & $3(2-4)$ & $3(2-4)$ \\
\hline Access: at least 1 ITN (a) & 89.9 & 93.8 & 90.9 & 83.6 & 96.1 & 91.4 & 87.7 \\
\hline $\begin{array}{l}\text { Intra-household saturation with ITNs: at least } 1 \text { ITN } \\
\text { for every } 2 \text { people (b) }\end{array}$ & 37.0 & 56.2 & 60.8 & 54.1 & 12.3 & 12.6 & 18.0 \\
\hline$C P R(95 \% C I)=a / b$ & $2.4(2.3-2.6)$ & $1.7(1.5-1.8)$ & $1.5(1.3-1.7)$ & $1.5(1.4-1.7)$ & $7.8(6.0-10.2)$ & $7.2(4.2-12.3)$ & $4.9(3.9-6.2)$ \\
\hline \multicolumn{8}{|l|}{ Placement status $^{\ddagger}$} \\
\hline All ITNs correctly hung & 46.5 & 50.4 & 56.4 & 54.6 & 38.5 & 43.2 & 36.3 \\
\hline At least 1 ITN correctly hung (c) & 78.6 & 77.4 & 80.2 & 80.3 & 79.1 & 83.8 & 74.6 \\
\hline At least 1 ITN for every 2 people correctly hung (d) & 18.1 & 27.8 & 33.7 & 30.9 & 4.1 & 0 & 3.2 \\
\hline$C P R(95 \% C l)=c / d$ & $4.3(3.9-4.9)$ & $2.8(2.3-3.4)$ & $2.4(1.8-3.2)$ & $2.6(2.2-3.1)$ & $19.2(11.0-33.5)$ & - & $23.1(11.7-45.9)$ \\
\hline \multicolumn{8}{|l|}{ Physical integrity ${ }^{\ddagger}$} \\
\hline All ITNs in very good condition & 62.1 & 68.1 & 67.3 & 71.6 & 53.3 & 44.6 & 54.8 \\
\hline At least 1 ITN in very good condition (e) & 92.0 & 93.8 & 85.2 & 92.4 & 92.4 & 86.5 & 93.2 \\
\hline $\begin{array}{l}\text { At least } 1 \text { ITN for every } 2 \text { people in very good } \\
\text { condition (f) }\end{array}$ & 25.1 & 40.3 & 39.6 & 40.7 & 6.5 & 4.1 & 6.5 \\
\hline$C P R(95 \%(I)=e / f$ & $3.7(3.3-4.0)$ & $2.3(2.0-2.7)$ & $2.2(1.7-2.8)$ & $2.3(2.0-2.6)$ & $14.2(9.2-21.9)$ & $21.3(7.0-64.9)$ & $14.4(9.0-23.2)$ \\
\hline
\end{tabular}

Notes: $\mathrm{CPR}=$ crude proportion ratio; $95 \% \mathrm{Cl},=95 \%$ confidence interval; $a$, denominator = all households; $b$, among households owning at least one ITN; Proportions or numbers in bold $=\mathrm{p}$ value $<0.05$ (comparing urban/peri-urban/rural areas); ${ }^{\dagger}$ Assessed taking into account all the 4,811 ITNs reported; ${ }^{\ddagger}$ Assessed taking into account only the 3,006 ITNs observed by the surveyors.

with ITNs was substantial, especially in large households. All crude proportion ratios were highly significant, varying between 1.5 in peri-urban small households and 7.8 in rural large households. Overall, intra-household saturation with ITNs was heterogeneous across villages (Figure 1) and urban sectors $(\mathrm{p}=0.046)$.

Surveyors were allowed by household heads to observe about two-thirds of the ITNs (Table 1). Half of the ITNs seen were correctly hung (Table 2), while at least one ITN was correctly hung in about four out of five households. The proportion of ITNs correctly hung for every two persons was much lower, ranging from zero in large households in peri-urban areas to about one-third in small households in those areas. Among small households, the proportion with one ITN correctly hung was two times higher than the proportion of households with at least one ITN for every two members correctly hung. The crude proportion ratio reached 19 among large households.

In two-thirds of the homes visited, all the ITNs observed were in very good physical condition (Table 2). But here, too, values decreased substantially when the indicators took into consideration saturation. The ratio between the proportion of households having at least one ITN in very good condition and the proportion of households with one ITN for every two people in very good physical condition and the proportion of households having at least one ITN in very good condition was two in small households and 14 to 20 in large ones. The proportion of households with impaired ITNs was not significantly different between rural, peri-urban, and urban areas.

\section{Use of ITNs to protect under-five children}

Among households possessing at least one ITN, 70\% of the under-five children had been placed under an ITN the night preceding the survey. There was no significant difference in level of use by location of residence (rural, peri-urban, urban) or household size (small, large). However, in each of the three settings, the use of ITNs was significantly lower in large households than it was in small ones (Figure 2). Statistical models conducted on the subsample of large households showed that use of ITNs was significantly higher when there was at least one ITN for every two members, when the child had an episode of illness in the preceding two weeks, and when the mother had taken actions to control vector proliferation (Table 3). Use in small households was significantly higher when the family held agricultural land (a proxy for living in an environment that favours vector proliferation) and 


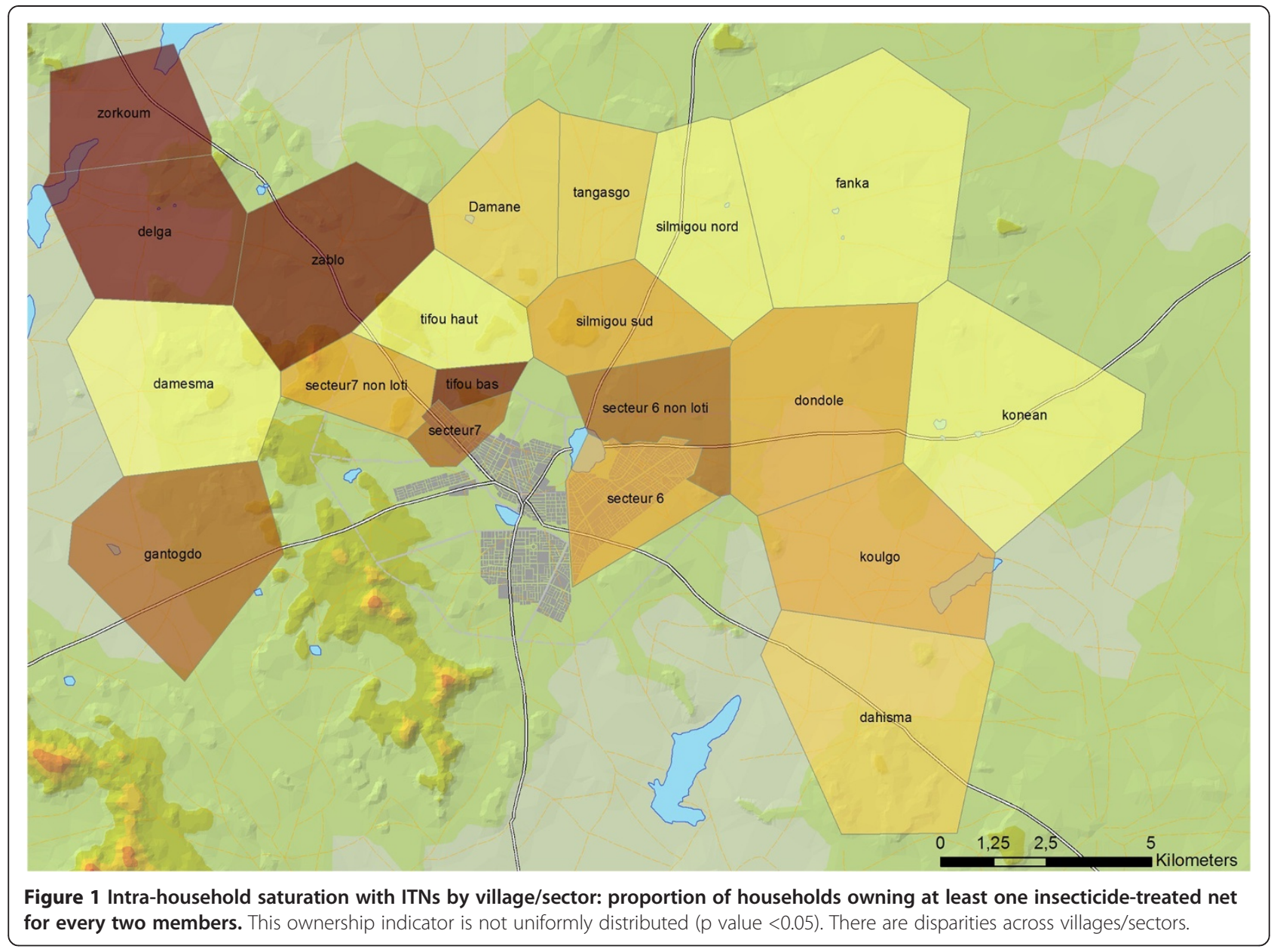

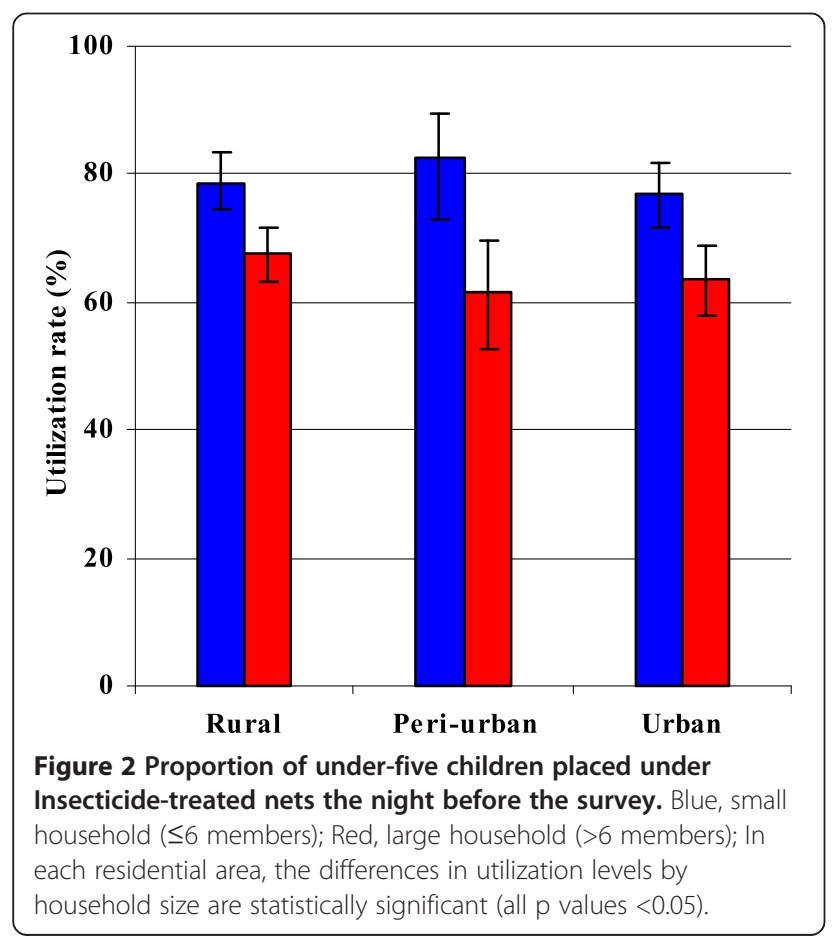

when the child was 12 to 23 months of age. The proportion of children who slept under an ITN was not significantly associated in this survey with variables such as residential area, cattle ownership, access to safe drinking water or private toilets, and proximity to lakes or stagnant water.

\section{Discussion}

The majority of the households (90\%) owned bed nets. However, there was a large gap between ownership of at least one ITN and intra-household saturation with ITNs. As anticipated, the needs in bed nets remained clearly unfulfilled, particularly in large households, where there was very low intra-household saturation with ITNs (20\%). With this low coverage, limited impacts on malaria transmission are to be expected, even if bed net use were optimal. Low saturation rates in large households following the distribution of a fixed number of bed nets have also been found in Tanzania [14]. The allocation process needs to be rethought and based on household size to increase access to bed nets in crowded households [22]. ITN placement and physical condition were better in small households, where intra-household saturation with ITNs was higher and competition for nets less 
Table 3 Insecticide-treated nets (ITN) utilisation to protect under-five children

\begin{tabular}{|c|c|c|}
\hline & $\begin{array}{c}\text { Model 1: } \\
\text { Small household } \\
(\leq 6 \text { members, } n=647)\end{array}$ & $\begin{array}{c}\text { Model 2: } \\
\text { Large household } \\
\text { (>6 members, } n=959)\end{array}$ \\
\hline \multicolumn{3}{|l|}{ Fixed effects } \\
\hline Intercept (estimate, SE) & $0.55(0.51)$ & $0.22(0.46)$ \\
\hline \multicolumn{3}{|l|}{ OR $(95 \% \mathrm{Cl})$} \\
\hline Intra-household saturation with ITNs: At least 1 ITN for every 2 people ${ }^{\dagger}$ & $1.6(1.02-2.58)$ & $1.9(1.07-3.42)$ \\
\hline Vector control activities ${ }^{\ddagger}$ & $0.9(0.58-1.44)$ & $1.5(1.07-2.16)$ \\
\hline At least 1 episode of child illness during the preceding 2 weeks $^{P}$ & $1.5(0.92-2.56)$ & $1.5(1.03-2.12)$ \\
\hline \multicolumn{3}{|l|}{ Residential area } \\
\hline Peri-urban versus urban & $1.4(0.59-3.33)$ & $0.9(0.47-1.69)$ \\
\hline Rural versus urban & $1.0(0.41-2.22)$ & $1.2(0.67-2.14)$ \\
\hline Ownership of agricultural land & $1.9(1.10-3.30)$ & $0.9(0.57-1.32)$ \\
\hline Ownership of any cattle $\mathrm{f}^{£}$ & $0.8(0.48-1.41)$ & $1.3(0.70-2.24)$ \\
\hline Access to safe drinking water & $1.2(0.60-2.30)$ & $1.2(0.75-1.94)$ \\
\hline Access to private toilets & $0.9(0.45-1.62)$ & $0.8(0.49-1.15)$ \\
\hline Distance to nearest lake or stagnant water point $(<1000 \mathrm{vs.} \geq 1000 \mathrm{~m})$ & $1.3(0.80-2.17)$ & $0.9(0.65-1.32)$ \\
\hline \multicolumn{3}{|l|}{ Children's age (months; reference $=0-11$ ) } \\
\hline $12-23$ & $2.2(1.10-4.55)$ & $1.3(0.78-2.28)$ \\
\hline $24-35$ & $2.0(0.98-3.94)^{*}$ & $1.1(0.66-1.82)$ \\
\hline $36-47$ & $1.6(0.81-3.11)$ & $1.1(0.67-1.84)$ \\
\hline $48-59$ & $1.3(0.80-2.17)$ & $1.0(0.60-1.75)$ \\
\hline \multicolumn{3}{|l|}{ Random effect } \\
\hline Household (estimate, SE) & $0.91(0.40)$ & $0.96(0.20)$ \\
\hline Intra-class correlation (95\% Cl) & $20.1(4.3-58.7)$ & $21.7(10.8-39.0)$ \\
\hline
\end{tabular}

Notes: SE = Standard error; OR = Odds ratio; $95 \% \mathrm{Cl}=95 \%$ confidence interval; Bold $=\mathrm{p}$ value $<0.05 ;{ }^{*} \mathrm{P}$ value $<0.10 ;{ }^{\dagger}$ Among households owning at least one ITN, unadjusted OR $(95 \% \mathrm{Cl})=1.71(1.09-2.69)$ in small households and $1.84(1.04-3.27)$ in large ones; ${ }^{\ddagger}$ Cleaning house, elimination of stagnant water and larval sites around the house by the mother of the under-five children; ${ }^{\mathrm{P}}$ Any illness; ${ }^{\mathrm{f}}$ Beef, camel, goat, horse, pig or sheep.

perceptible. Therefore, providing more nets per household would likely enhance their placement [23] and preserve their physical condition against rapid deterioration.

These results offer an opportunity to reflect on how to estimate ITN needs and monitor the outcomes of mass campaigns. Intra-household saturation with ITNs, even though it is an imperfect indicator, is clearly a more informative indicator of access than the commonly used measure of possession of at least one ITN per household $[8,13]$ which does not take into account household size or sleeping places and consequently does not precisely indicate the extent to which individuals have real access to the nets $[11,12,14]$. The gap between ownership rates per household and intra-household saturation with ITNs is so large that monitoring access to bed nets based on the former could be misleading. Similarly, the proportion of households with at least one ITN hanging or in very good physical condition also overestimates individuals' access to bed nets and, ultimately, population levels of protection. Here, too, saturation-based indicators might be more accurate in monitoring access to bed nets. Finally, because
ITN access depends on fulfillment of needs, proper placement, and good physical condition of the nets, and not just on the level of household ownership, an accurate understanding of access to bed nets and the assessment of campaign outcomes should be based on appropriate measurements of these three components.

Depending on the geo-spatial context and the size of the household, two-thirds to three-quarters of under-five children had slept under an ITN the previous night. As has been observed in other studies, more children were placed under ITNs in households with higher saturation rates $[12,24,25]$. In other words, children's protection is clearly linked to access to bed nets. ITN use was also higher in households where mothers cleaned the house and eliminated stagnant water and larval sites in the homestead. This suggests that actions by mothers to decrease mosquito density tend to be undertaken jointly with actions to protect the child and might reflect a more general concern among mothers about malaria prevention at home. Further research will eventually help in better understanding the web of relationships 
between vector control actions, ITN use, and malaria morbidity.

Children who had recent episodes of any illness were more likely to have been placed under bed nets the night before the survey. The reasons behind that observation are not yet clear and would require further investigations. It may be that some parents placed children presenting an episode of fever under the nets because they believed it would prevent progression of the episode to severe states [26-28]. Further qualitative studies are needed to understand the relationship between bed net use and children's conditions.

ITNs were used more for children aged 12-23 months than for those under 12 months, particularly in small households. Sleeping arrangements can partly explain this result. Baume and Marin reported that parents consider children under 24 months of age to be more vulnerable to malaria and often place them in priority under bed nets [24]. Finally, ITN use was not associated with residential area or household characteristics, such as cattle ownership or access to safe drinking water or private toilets. This result was expected because, apart from not taking into account household size, mass distribution campaigns of fixed numbers of bed nets generally reduce inequities in ownership and use $[10,13]$.

\section{Limitations}

Because there were no data available before the campaign, the extent to which the 2010 distribution campaign improved ITN coverage and use in the communities surveyed was not estimated. Such a baseline would have been helpful in assessing changes in ITN access and use attributable to the campaign. A second limitation was in the set of covariates available for the study of factors associated with the ITN use. In particular, it is common to check for the influence of mother's education on use. Unfortunately, there were too many missing values on education in the dataset to incorporate this variable into the model. However, the rate of education of adult women in these communities is low (only $12.5 \%$ of mothers had gone to school), and it is expected that education would not be a strong modifier in the model. Finally, there are reasons to believe the rates of ITNs hung and of ITNs in very good condition were somewhat overestimated. Often, surveyors were not allowed to enter the home and observe the bed nets themselves (37.5\% of the ITNs were not observed). It is reasonable to assume that in some cases, respondents did not want to let the surveyor see bed nets that were not hung or that were impaired.

\section{Conclusion}

From this study, some lessons related to the recent mass distribution campaign can be derived. First, ownership rates were high, but real access to bed nets remained limited. The allocation process clearly acted as a constraint that disadvantaged large families, who tend to live in rural, highly exposed areas. The allocation process should achieve acceptable levels of intra-household saturation with ITNs and fulfill populations' needs in terms of protection against malaria transmission. Second, real access to bed nets implies not only that they are available, but also that they are properly installed and in good condition. In general, campaign organizers do not pay enough attention to these critical issues. Finally, more post-campaign sensitization initiatives targeting mothers' awareness and preventive practices could eventually contribute to more effective use of bed nets and higher levels of protection against transmission.

\section{Competing interests}

The authors declare that they have no competing interests.

\section{Authors' contributions}

SD drafted the paper. SD and SH conducted the analyses. SH, VR, and SK developed and led the research program in which this study was embedded. TD prepared and managed the data. EB performed the spatial analyses. All authors reviewed and approved the manuscript.

\section{Acknowledgments}

The authors thank all the head physicians and their teams, the personnel of the medical centres, and the team of professionals and investigators of Kaya HDSS, who participated in preparing and conducting the survey. The authors also thank their collaborators and the health authorities, as well as Donna Riley for editing the manuscript. This work was carried out with a grant from the Canadian Institutes of Health Research (CIHR, grant \#40165).

\section{Author details}

'University of Montreal Hospital Research Centre (CRCHUM), Montreal, Canada. ${ }^{2}$ Department of Social and Preventive Medicine, University of Montreal, Montreal, Canada. ${ }^{3}$ Institut de Recherche pour le Développement (IRD), Ouagadougou, Burkina Faso. ${ }^{4}$ Institut de Recherche en Sciences de la Santé (IRSS) du CNRST, Ouagadougou, Burkina Faso.

Received: 17 June 2014 Accepted: 1 September 2014 Published: 4 September 2014

\section{References}

1. WHO: World Malaria Report. Geneva: World Health Organization; 2012.

2. Murray CJL, Rosenfeld LC, Lim SS, Andrews KG, Foreman KJ, Haring D, Fullman N, Naghavi M, Lozano R, Lopez AD: Global malaria mortality between 1980 and 2010: a systematic analysis. Lancet 2012, 379:413-331.

3. Centers for Disease Control and Prevention: CDC in Burkina Faso - Factsheets. Atlanta: 2013.

4. Ministère de la santé: Evaluation de la couverture de la population par les moustiquaires imprégnées d'insecticides après la campagne de distribution universelle en 2010 et Recours thérapeutiques pour les soins des épisodes fébriles chez les enfants de moins de 5 ans au Burkina Faso, Rapport final Version du 4 Juillet 2012. Ouagadougou: Ministère de la santé, Centre national de recherche et de formation sur le paludisme; 2012.

5. Bhattarai A, Ali AS, Kachur SP, Martensson A, Abbas AK, Khatib R, Al-Mafazy AW, Ramsan M, Rotllant G, Gerstenmaier JF, Molteni F, Abdulla S, Montgomery SM, Kaneko A, Björkman A: Impact of artemisinin-based combination therapy and insecticide-treated nets on malaria burden in Zanzibar. PLoS Med 2007, 4:e309.

6. Pluess B, Tanser FC, Lengeler C, Sharp BL: Indoor residual spraying for preventing malaria. Cochrane Database Syst Rev 2010, 4, CD006657.

7. Lim SS, Fullman N, Stokes A, Ravishankar N, Masiye F, Murray CJL, Gakidou E: Net benefits: a multicountry analysis of observational data examining associations between insecticide-treated mosquito nets and health outcomes. PLoS Med 2011, 8:e1001091. 
8. O'Meara WP, Mangeni JN, Steketee R, Greenwood D: Changes in the burden of malaria in sub-Saharan Africa. Lancet Infect Dis 2010, 10:545-555.

9. Eisele TP, Larsen DA, Walker N, Ciburskis RE, Yukich JO, Zikusooka CM, Steketee RW: Estimates of child deaths prevented from malaria prevention scale-up in Africa 2001-2010. Malar J 2012, 11:93.

10. Thwing J, Hochberg N, Vanden Eng J, Issifi S, Eliades MJ, Minkoulou E, Wolkon A, Gado H, Ibrahim O, Newman RD, Lama M: Insecticide-treated net ownership and usage in Niger after a nationwide integrated campaign. Trop Med Int Health 2008, 13:827-834.

11. Thwing Jl, Perry RT, Townes DA, Diouf MB, Ndiaye S, Thior M: Success of Senegal's first nationwide distribution of long-lasting insecticide-treated nets to children under five - contribution toward universal coverage. Malar J 2011, 10:86.

12. Tokponnon FT, Aholoukpe B, Denon EY, Gnanguenon V, Bokossa A, N'guessan R, Oke M, Gazard DK, Akogbeto MC: Evaluation of the coverage and effective use rate of long-lasting insecticidal nets after nation-wide scale up of their distribution in Benin. Parasit Vectors 2013, 6:265.

13. Ye Y, Patton E, Kilian A, Dovey S, Eckert E: Can universal insecticide-treated net campaigns achieve equity in coverage and use? The case of northern Nigeria. Malar J 2012, 11:32.

14. West PA, Protopopoff N, Rowland MW, Kirby MJ, Oxborough RM, Mosha FW Malima R, Kleinschmidt I: Evaluation of a national universal coverage campaign of long-lasting insecticidal nets in a rural district in north-west Tanzania. Malar J 2012, 11:273.

15. Ridde V, Druetz T, Poppy S, Kouanda S, Haddad S: Implementation fidelity of the national malaria control program in Burkina Faso. PLoS One 2013, 8:e69865.

16. Kilian A, Koenker H, Bada E, Onyefunafoa EO, Selby RA, Lokko K, Lynch M: Universal coverage with insecticide-treated nets - applying the revised indicators for ownership and use to the Nigeria 2010 malaria indicator survey data. Malar J 2013, 12:314.

17. Kouanda S, Bado A, Yaméogo M, Nitièma J, Yaméogo G, Bocoum F, Millogo T, Ridde V, Haddad S, Sondo B: The Kaya HDSS, Burkina Faso: a platform for epidemiological studies and health programme evaluation. Int J Epidemiol 2013, 42:741-749.

18. Arnaud M, Emery X: Estimation et Interpolation Spatiale. Paris: Hermes Science Publication; 2000.

19. Eyobo ME, Awur AC, Wani G, Julla Al, Remijo CD, Sebit B, Azairwe R, Thabo O, Bepo E, Lako RL, Riek L, Chanda E: Malaria indicator survey 2009, South Sudan: baseline results at household level. Malar J 2014, 13:45.

20. Esri: ArcGIS 10 Transforms the Way People Use GIS: New Release Simplifies Your Work, Provides New Ways to Share Information, Supplies GIS in the Cloud, and Much More. USA: Press release; 2010. http://www.esri.com/news/releases/ 10_2qtr/arcgis10-download.html.

21. StataCorp: Announcing Stata 13. USA: Press release; 2013. http://www.stata. com/stata-news/statanews.28.special.pdf.

22. Kilian A, Boulay $M$, Koenker $H$, Lynch $M$ : How many mosquito nets are needed to achieve universal coverage? Recommendations for the quantification and allocation of long-lasting insecticidal nets for mass campaigns. Malar J 2010, 9:330.

23. Vanden Eng JL, Thwing J, Wolkon A, Kulkarni MA, Manya A, Erkine M, Hightower A, Slutsker L: Assessing bed net use and non-use after long-lasting insecticidal net distribution: a simple framework to guide programmatic strategies. Malar J 2010, 9:133.

24. Baume CA, Marin MC: Intra-household mosquito net use in Ethiopia, Ghana, Mali, Nigeria, Senegal, and Zambia: are nets being used? who in the household uses them? Am J Trop Med Hyg 2007, 77:963-971.

25. Graves PM, Ngondi JM, Hwang J, Getachew G, Gebre T, Mosher AW, Patterson AE, Shargie EB, Tadesse Z, Wolkon W, Reithinger R, Emerson PM, Richards FO Jr: Factors associated with mosquito net use by individuals in households owning nets in Ethiopia. Malar J 2011, 10:354.

26. Oberländer L, Elverdan B: Malaria in the United Republic of Tanzania: cultural considerations and health-seeking behaviour. Bull World Health Organ 2000, 78:1352-1357.
27. Toé LP, Skovmand O, Dabiré KR, Diabaté A, Diallo Y, Guiguemdé TR, Doannia JMC, Akogbeto M, Baldet T, Gruénais M-E: Decreased motivation in the use of insecticide-treated nets in a malaria endemic area in Burkina Faso. Malar J 2009, 8:175.

28. Hlongwana KW, Mabaso MLH, Kunene S, Govender D, Maharaj R: Community knowledge, attitudes and practices (KAP) on malaria in Swaziland: a country earmarked for malaria elimination. Malar J 2009, 8:29.

doi:10.1186/1475-2875-13-353

Cite this article as: Diabaté et al:: Insecticide-treated nets ownership and utilization among under-five children following the 2010 mass distribution in Burkina Faso. Malaria Journal 2014 13:353.

\section{Submit your next manuscript to BioMed Central and take full advantage of:}

- Convenient online submission

- Thorough peer review

- No space constraints or color figure charges

- Immediate publication on acceptance

- Inclusion in PubMed, CAS, Scopus and Google Scholar

- Research which is freely available for redistribution

Submit your manuscript at www.biomedcentral.com/submit
C) BioMed Central 